ח

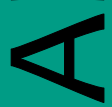

n

Ш

Z

O

$\underline{-}$

$F$

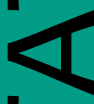

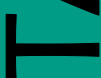

ه

Ш

n

n

$\overline{0}$
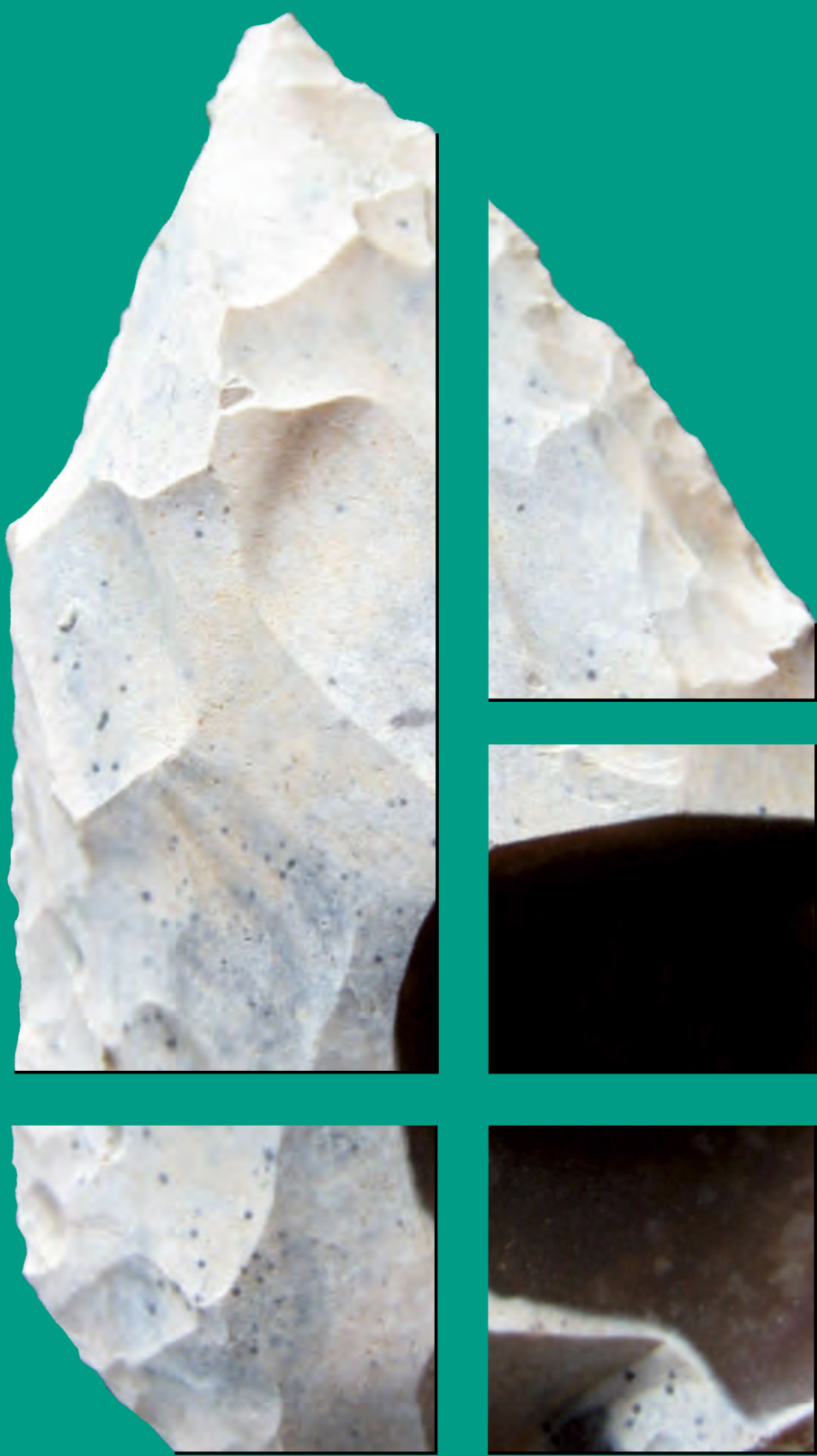

Ser. 3. No.9.| 2021 


\section{Dissertationes Archaeologicae ex Instituto Archaeologico}

Universitatis de Rolando Eötvös nominatae

Ser. 3. No. 9.

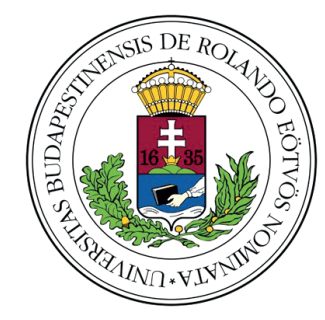

Budapest 2021 


\section{Dissertationes Archaeologicae ex Instituto Archaeologico Universitatis de Rolando Eötvös nominatae}

Ser. 3. No. 9.

Editor-in-chief

Dávid BARTus

Editorial board

László Bartosiewicz (Stockholm University, Stockholm)

Ondřej Chvojкa (University of South Bohemia, České Budějovice)

Zoltán Czajlik (Eötvös Loránd University, Budapest)

Mario Gavranović (Austrian Arhaeological Institute AAS, Vienna)

Hajnalka Herold (University of Exeter, Exeter)

Klára Kuzmová (University of Trnava, Trnava)

Tina Milavec (University of Ljubljana, Ljubljana)

Gábor V. Szabó (Eötvös Loránd University, Budapest)

Tivadar VIDA (Eötvös Loránd University, Budapest)

Technical editor

Gábor VÁcZI

Proofreading

Eszter TímÁr

Strobe DrIVER

Borbála MoHÁcsI

Fruzsina NÉMETH

Eli J. S. WeAVERDYCKE

Aviable online at http://ojs.elte.hu/dissarch

Contact: dissarch@btk.elte.hu

ISSN 2064-4574 (online)

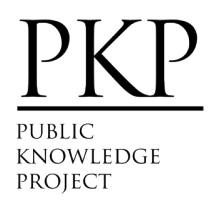

(c ELTE Eötvös Loránd University, Institute of Archaeological Sciences

Layout and cover design: Gábor Váczi

Budapest 2021 


\section{CONTEnTs}

\section{ARTiCles}

Attila PÉNTEK - Norbert FARAgó

Palaeolithic and Mesolithic assemblages from Tunisia

Attila PÉNTEK - Norbert FARAGó

Some remarks on a German chipped stone lithic assemblage of uncertain origin in the collection of the Institue of Archaeological Sciences, Eötvös Loránd University

László Gucsi

Technological observations on a Late Copper Age ceramic assemblage

from Hódmezővásárhely-Kopáncs-Olasz-tanya, Hungary

János Gábor TARBAY

101

A Koszider Period Sword from Tornyospálca-Sírkútgaz (Szabolcs-Szatmár-Bereg County, Hungary)

Ábel GARCZIK

Dolia in the Middle La Tène Period of the Carpathian Basin in the light of new finds from Perkáta-Nyúli-dűlő

Lajos JuHÁsz

An exceptional Sarmatian cast medallion with star and crescent

Gabriella G. DeLBó

New data on the Pannonian glazed casserole handles

Csilla SÁró

The fibula production of Brigetio: Model, semi-finished products, and failed castings

Anita BENES

New data on the capacity of the Roman aqueduct of Brigetio

Melinda SzABó

Status or Role? Differences between the Social Status and Role in Brigetio

Krisztina HoppáL

Roman engraved gems from Southeast Asia 


\section{FiELD REPORTS}

Bence SIMON - Ferenc BARNA

Another barrel-lined well a road section and late Roman graves from Brigetio

Rita RAKONCZAY

Trial excavations in mediaeval churches of Kishartyán, Kisterenye, Mátranovák and Szuha in Nógrád County 2021

\section{Thesis Review Articles}

Tamás KEszi

The change of the pottery style of the Mako and Nagyrév cultures in the Early Bronze Age:

The settlement in Iváncsa-Lapos

Linda Dobosi

Building techniques and building materials in Brigetio:

With the virtual reconstruction of House I/a of the civil town of Brigetio

Csilla SÁRó

Tradition and Romanization by the attire of the Eraviscus tribe 


\title{
Some remarks on a German chipped stone lithic assemblage of uncertain origin in the collection of the Institue of Archaeological Sciences, Eötvös Loránd University
}

\author{
Attila PÉntek \\ Independent researcher \\ attila.pentek@yahoo.com
}

\author{
Norbert FARAGó \\ Institute of Archaeological Sciences, \\ Eötvös Loránd University \\ norbert.farago@gmail.com
}

Received 17 December 2021 | Accepted 7 January 2022 | Published 2 March 2022

\begin{abstract}
András Marton has recently come into the possession of a small, chipped stone assemblage from the legacy of a German amateur mineral collector from Hamburg. Unfortunately, very little is known about the deceased and his collection. A part of the finds, including tools, was donated to the Institute of Archaeology of the Eötvös Loránd University. The lithic assemblage contains a total of 27 chipped stone artefacts made exclusively of Baltic flint. Concerning the raw material used, these flint varieties with the banded structure are rather unusual in Schleswig-Holstein. They are much more likely to originate from Lower Saxony or perhaps Mecklenburg-Western Pomerania. Apart from the general technological description of the assemblage, some pieces from these non-formal tools have been selected for a detailed description. The application of the "direct percussion with a hard hammer" technique and the presence of the thick artefacts contradict the Palaeolithic or Mesolithic origin of the assemblage, except for the flint axe ("Kernbeil"), which has a possible Mesolithic association. Alternatively, if the edges of the artefacts are not worn out or rolled, then along the edges of all artefacts traces of some kind of "cryoturbation retouch" are observable. In this case, the Palaeolithic dating of the finds is more plausible.

Keywords: chipped stone artefacts, Mesolithic, Neolithic, Trichterbercher culture, SchleswigHolstein
\end{abstract}

\section{Introduction}

András Marton (Mesterháza, Vas County, Western Hungary) has recently come into the possession of a small, chipped stone assemblage from the legacy of a German amateur mineral collector. Unfortunately, very little is known about the deceased. He lived in Hamburg (Northern Germany), but neither the detailed composition of the mineral collection nor its origin is known, not to mention the origin of the lithic artefacts. Consequently, it is impossible to restrict the collector's collecting area or areas, which could be a good starting point for processing. András Marton has donated a part of the finds, including tools, to the Institute of Archaeology of the Eötvös Loránd University (ELTE). In the following, despite the uncertainty, we try to give a sketchy assessment of the lithic material based on indirect considerations. 


\section{General description of the lithic assemblage}

The lithic assemblage contains a total of 27 chipped stone artefacts. The raw material of the finds is Baltic flint (Upper Cretaceous Senonian flint), which is characterized by excellent knapping properties. Although the degree of patination cannot be considered a chronological marker in the case of most lithic raw materials, it is necessary to mention that generally, both faces of the artefacts are fairly patinated. The colour of the patina is generally light-grey. For two artefacts, the patination is asymmetric (one face is more patinated than the other), and there are only four artefacts with a relatively fresh, unpatinated surface. A single artefact refers only to the supposed mixed nature of the assemblage. It is a chipped stone axe (Kernbeil in German), with a uniformly patinated surface.

A good deal of the artefacts is covered with iron moulds or rust stains of brown or reddish colour caused by iron dissolved in water (e.g., Fig. 1,2,4; Fig. 2,1-3; Fig. 3). The rust-like spots are very often formed on the edges of the artefacts. It might have been due to post-depositional processes, such as iron-oxide aggregation or due to permanent contact with ferrous minerals.

Some of the artefacts have a banded structure (bandings) (e.g., Fig. 4,1-3; Fig. 5,3; Fig. 6,1) or carry smaller or larger-sized inclusions of skeletons of marine organisms (e.g., Fig. 1,1,3; Fig. 4,1-4; Fig. 5,1-2). The artefact in Fig. 6,5 has the most spectacular inclusion.

From a technological point of view, regardless of their size, the artefacts suggest the use of the "direct percussion with a hard hammer" technique. There is no evidence of bipolar lithic reduction; all debitage products show one-directional flaking scars only. They were possibly struck from unipolar cores with a single striking platform. The striking platforms are unprepared; there are only dim traces of either dorsal reduction or abrasion (e.g., Fig. 1,4; Fig. 5,1; Fig. 6,1-2). The butt of the debitage products is usually irregular in shape and always flat. It is in all cases the natural surface of the raw material. The bulbs of the artefacts are generally large and pronounced; the ripples (concentric waves) are well visible (e.g., Fig. 5, 1). ${ }^{1}$ There is a single artefact with a double bulb. ${ }^{2}$ The presence of bulb scars, which corresponds to the formation of a secondary or parasitical flake, is very common. ${ }^{3}$ There are 11 flakes among the finds. The remaining 15 chipped artefacts are either blades or tools made on a blade. Both the flakes and the blades are strikingly thick. The number of offset (off-axis) debitage products is rather high (e.g., Fig. 1,2-3; Fig. 2,2; Fig. 4,1-2; Fig. 5,1-3; Fig. $6,2,5)$. Overall, the assemblage gives the impression of a blade or elongated flake-oriented lithic industry intending to obtain potential working edges for as long as possible.

From a typological point of view, the steep (abrupt) and rather coarse (knife-like) retouching of the edges is noticeable on some of the artefacts, as well as other modifications, such as burin-blow-like protrusions (e.g. Fig. 1,1,4; Fig. 4,2). The majority of the tools are rather atypical, non-formal tools and can hardly be fitted in any typological system. Some pieces of these non-formal tools have been selected for a detailed description of the 27 chipped stone artefacts. The composition of the assemblage vindicates certain "selectivity"; the general impression of the collection is that almost only those artefacts were collected that have been thought of as being tools. Firstly, the artefacts retained in the possession of András Marton will be discussed. Thereafter, the description of those artefacts follows that now belong to the ELTE collection. 


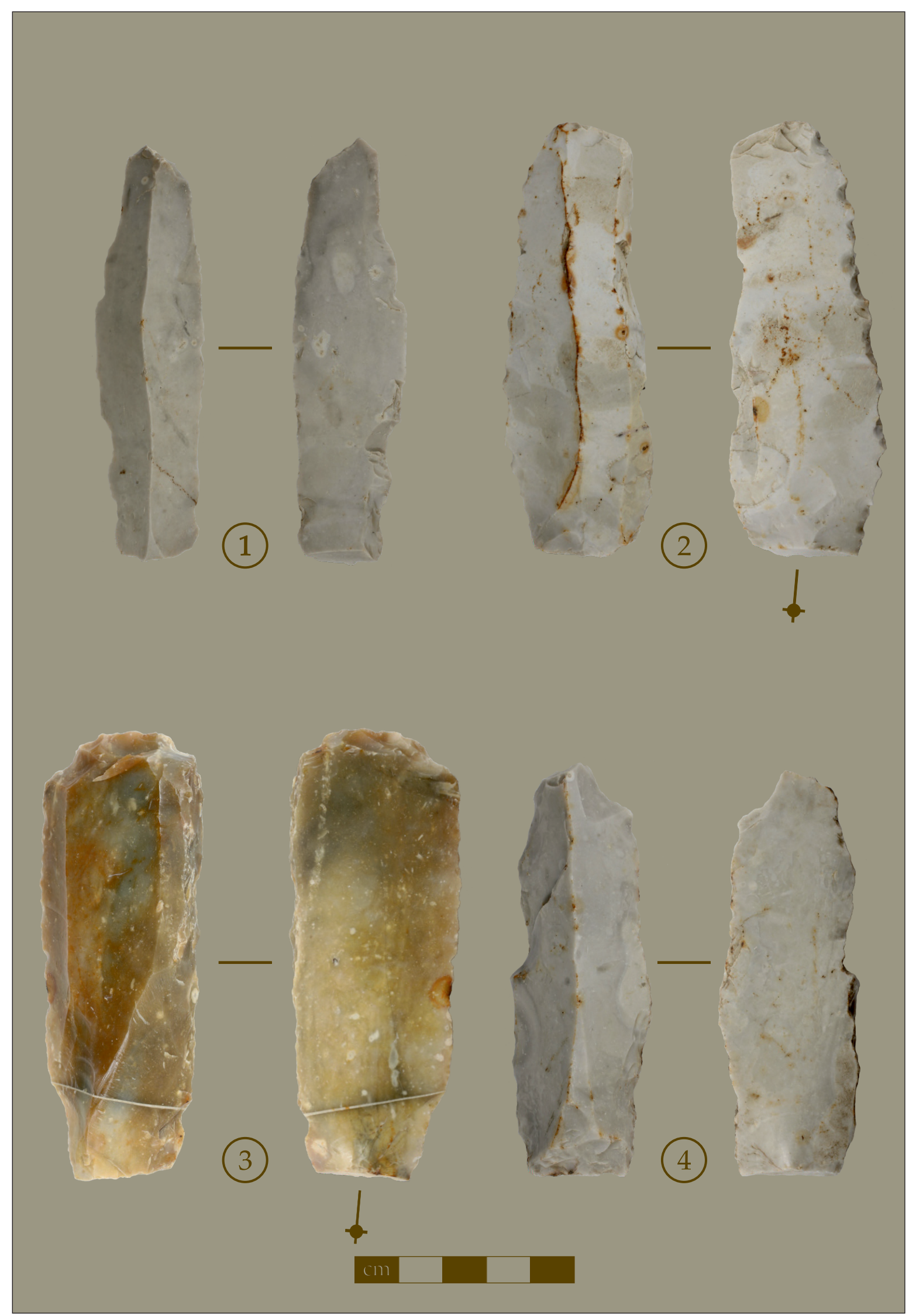

Fig. 1. Selected artefacts. 1 - combination tool (retouched blade and burin), 2, 3 - retouched blades with wedge-like distal end, 4 - retouched blade. 
The lithic assemblage of András Marton

In Fig. 1,1, there is a combination tool made on a regular blade with a triangular cross-section. The side profile of the blade is curved. The proximal part was intentionally broken. The oblique distal end is abruptly retouched in a length of $14.0 \mathrm{~mm}$. On the distal end of the left lateral edge, there is a burin-blow-like, $34.4 \mathrm{~mm}$ long removal. This section is inversely retouched with a semi-abrupt retouch in a length of $20.0 \mathrm{~mm}$. On the proximal end of the left edge, we can see the above-mentioned burin-blow-like protrusions with intensive use-wear traces. The dimensions are $96.6 \times 35.8 \times 10.2 \mathrm{~mm}$.

The tool in Fig. 1,2 has an asymmetric cross-section with two curved ridges and a straight side profile. The somewhat oblique straight distal end is wedge-like. There are some small direct removals; on the lower face, there are some irregular thinning removals. The steep and high left edge shows no traces of any elaboration. In contrast, the left edge shows use-wear traces in the form of rather large chips, which are likely to evidence the cutting and/or scraping of some hard material. The dimensions are $96.8 \times 34.7 \times 12.5 \mathrm{~mm}$.

The tool in Fig. 1,3 was made on a chunky blade with a strikingly asymmetric cross-section and a slightly curved side profile. The slightly curved distal end is wedge-like; both the direct and inverse removals are rather large, making a zigzaggy line of the distal edge. The steep right edge is retouched in its entire length. It was several times renewed and shows coarse use-wear traces as a result of scraping hard material. The half-steep left edge is finely retouched. The dimensions are $100.3 \times 37.7 \times 17.9 \mathrm{~mm}$.

In Fig. 1,3, the tool was made on a regular blade with a triangular cross-section and a straight side profile. The overhang (the projection crowning a core ${ }^{4}$ ) was eliminated by small removals, probably after the blade itself had been detached. On the left side of the distal end, there are three small removals; on the right side, there is a large removal. The "use-related retouch" indicates a certain working function of the distal end. The left edge has an irregular line; it is abruptly retouched in the entire length. On the right edge, the proximal end is retouched with a semi-abrupt retouch in a length of $36.8 \mathrm{~mm}$. On the other hand, on the lower face, the distal end of the edge carries several traces of use-retouch as a clear indication that the entire edge was used for some unknown work. The dimensions are $91.5 \times 31.1 \times 18.5 \mathrm{~mm}$.

The proximal end of the tool in Fig. 2,1 was intentionally broken. The blank for the tool manufacturing may have been a wide flake, having two ridges and an asymmetrical cross-section. The side profile is almost straight, only the very end has a slight curvature. The distal end was elaborated quasi end-scraper-like with several irregular removals. The semi-steep curved left edge is finely retouched. The proximal end of the right edge is retouched in a length of $11.7 \mathrm{~mm}$, and there is also a small-sized retouched notch. The distal part of this edge is heavily splintered partly due to "cryoturbation retouch", partly due to working of hard material. The dimensions are $84.9 \times 39.7 \times 12.5 \mathrm{~mm}$.

The tool in Fig. 2,2 was made on a chunky blade with an asymmetric (sub-trapezoid) cross-section and a slightly curved side-profile. The bulb was partly eliminated. On the distal end, on the lower face, there is a large flat, burin-blow-like removal. Small removals and use-related retouches are also observable. The half-steep, straight left edge is partially retouched. The thick right edge is doubly zigzaggy and abruptly retouched. This working edge was several times renewed; especially the midpart of the edge makes an obtuse angle with the lower face. The dimensions are $113.3 \times 42.3 \times 18.9 \mathrm{~mm}$. 


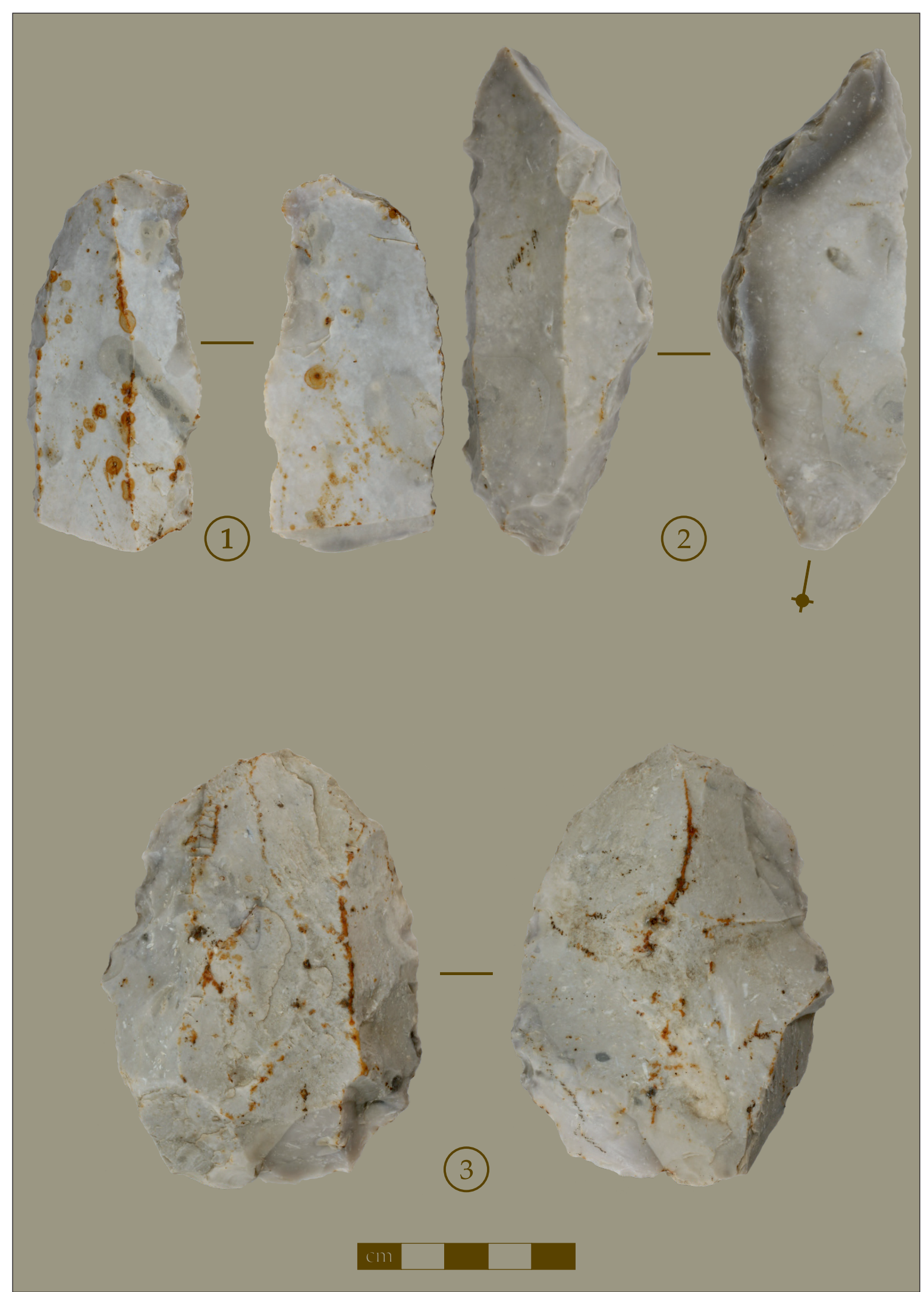

Fig. 2. Selected artefacts. 1 - retouched blade, 2 - combination tool (retouched blade and burin), 3 - atypical cleaver (hacheraux). 


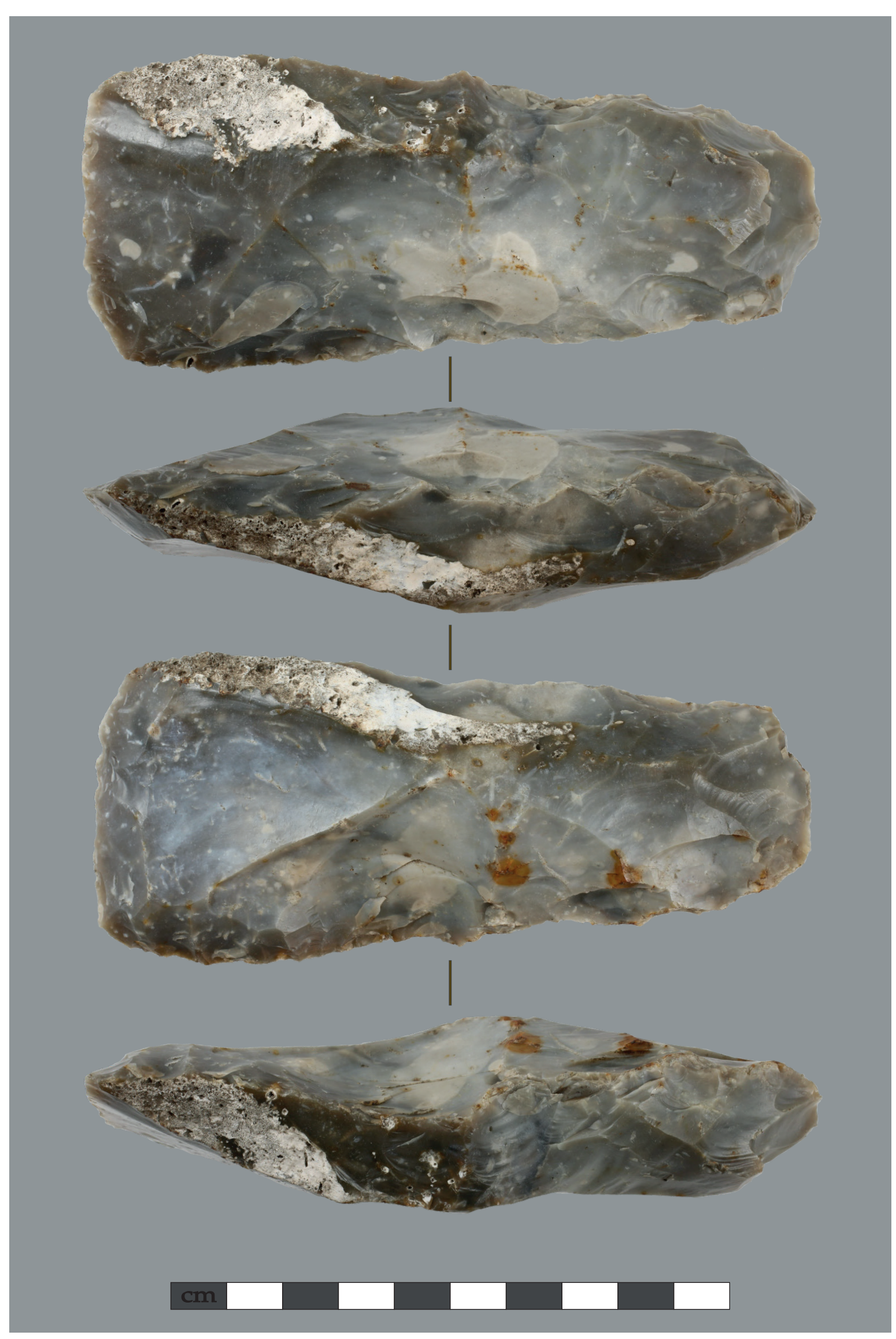

Fig. 3. Flint stone axe (Kernbeil). 
In Fig. 2,3, there is a large-sized raw material chunk, actually an expedient tool. All along the edges, there are traces, mostly in the form of use-retouch due to intensive use, probably as a "cleaver" (hacheraux). The edges were partially corrected by small removals or even by retouching. The dimensions are $95.9 \times 68.9 \times 19.9 \mathrm{~mm}$.

In Fig. 3, there is a flint stone axe (Kernbeil). Without having any starting point, the orientation of the core-axe in Fig. 3 is entirely arbitrary. From top-to-bottom, the assumed front face, the lower edge, the back face, and the upper edge are represented. The selected raw material nodule contains many inclusions of different sizes. Some small-sized rust stains of brown colour are visible. Probably due to the rather small size of the selected flint nodule, both the front face and the back face are partially covered in the unremoved pitted calcareous surface. Both faces are roughly elaborated with the absolute minimal effort. On the back face, an overlarge removal, likely a knapping accident is observable. The tool has a trapezoid side-view and both short edges served as working edges, showing traces of intensive use. The length is $125.4 \mathrm{~mm}$, the thickness is $30.5 \mathrm{~mm}$. The height varies between 32.8 and $57.6 \mathrm{~mm}$. Both ends of the longer working edge (ca. $44.6 \mathrm{~mm}$ ) are rounded; the shorter working edge is about $28.8 \mathrm{~mm}$. Based on the studies of Bo Madsen ${ }^{5}$ and Stefan Wenzel ${ }^{6}$, in the following, a summary of this particular object will be given.

Core-axe blades are struck from a piece of flint in such a way that they have approximately opposite side edges and a cutting edge. In the case of flake-axes, the basic shape of the axe blade was a thick flake or a flat raw material chunk or shatter, in which an acute-angled edge was used as a cutting edge, while the side edges were retouched steeply. The traditionally customary assignment of axe blades to the group of core tools or flake tools is difficult for individual pieces. Flake-axes comprise the remainder of the lower (ventral) surface of a flake or the split (cleavage) surface of a flat raw material piece. On the other hand, on core-axes, there is no remnant of a lower surface visible any more, even if they were obtained from a flake. In the case of core-axes, the rough form was roughly put into shape with hard blows on both sides of an elongated flint nodule or an elongated thick raw material piece. Occasionally, in a second manufacturing step, the raw piece was thinned by further blows, whereby a hammer made of antlers or other organic material is particularly suitable for the removals of flat flakes that reach far across the surface. Post-processing was carried out extremely sparingly, especially with the removal of small raw material pieces, if the axe had an almost usable shape due to the rough shaping. These pieces have generally many remains of natural cleavage surfaces. The cutting edge of the axe was often first formed by blows on both sides, then sharpened through a strike transversely to the longitudinal axis.

Core-axes were found several times still stuck in a device socket made of deer antlers with a hole in the shaft. ${ }^{7}$ Their cutting edge was perpendicular to the handle, which was inserted through a hole at the rear end of the antler socket. Based on numerous use-wear analyses carried out on stone axes, besides woodworking, animals were also cut up and hides cleaned with core-axes and flake-axes. ${ }^{8}$ Thus, they were used as multifunctional tools.

Core- and flake-axes are typical tools of the Mesolithic of southern Scandinavia and northern Central Europe. Their distribution area extends in the Mesolithic from the British Isles to Russia. Within Central Europe, some specimens from Hessen mark the southern limit of the distribution area. ${ }^{9}$

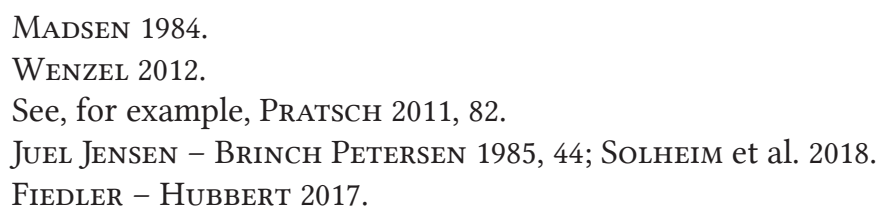


After all, core- and flake-axes also occur in Central and Northern Europe in the Neolithic. The frequent occurrence of these tools in the area of the Funnelbeaker culture (Trichter(-rand-)becherkultur in German; ca. 4,300-2,800 BC) can be seen as an indication of the adoption of the sedentary way of life by the population living there. ${ }^{10}$ The sporadic occurrence of atypical flake-axes on Linear Pottery (LBK) sites, as well as the frequent occurrence of core- and flake-axes in Middle and Early Neolithic settlements in Western Europe,${ }^{11}$ has the same message as the occurrence of stone axes in pre-Mesolithic times: coreand flake-axes were repeatedly produced in different regions and periods, without always having any tradition of producing such axe blades. Because the shape of the core- and flake-axes was often largely determined by the initial raw material piece and because these tools were used intensively and often re-sharpened, it is difficult to assign them to a specific period or culture. ${ }^{12}$

The rest of the artefacts in the possession of András Marton are mostly various-sized flakes with "cryoturbation retouch" or plough damage resembling continuous retouch.

\section{Lithic artefacts in the ELTE collection}

The tool in Fig. 4,1 was made on a chunky curved blade with an asymmetric (sub-triangular) cross-section and slightly wavy side-profile. The distal end is partially inversely retouched, in a form resembling an "end-scraper". The thick, half-steep, curved right edge is retouched in its entire length. This working edge was several times renewed; especially the distal part of the edge makes an obtuse angle with the lower face. The dimensions are $115.4 \times 34.2 \times 15.1 \mathrm{~mm}$.

There is a nicely elaborated combination tool in Fig. 4,2. It was made on an offset blade with a triangular cross-section and somewhat twisted profile. On the distal end of the left lateral edge, there are primary and secondary burin blows to be seen. The distal end of the curved right lateral edge is steeply (abruptly) retouched. The dimensions are $84.6 \times 31.8 \times 14.4 \mathrm{~mm}$.

There is a long, pointed semi-cortical secondary blade, probably associated with the initial stage of lithic reduction (Fig. 4,3). The blade has an asymmetric trapezoid cross-section and a slightly curved side profile. On the upper face, the curved thick right lateral edge is covered with the cortex of the flint core. A long flake scar, the trace of a previous long blade removal is visible. The proximal end of the blade was thinned through a small removal. It probably happened after the blade had been struck, so the remnant of the butt is rather small, providing the facility of accidental hafting. The left lateral edge has a typical fine use-retouch, suggesting a cutting activity of relatively soft material. The dimensions are $123.0 \times 31.9 \times 13.1 \mathrm{~mm}$.

In Fig. 4,4, there is the distal end of an intentionally broken blade. It has a slightly curved triangular cross-section and a straight side profile. Both edges have irregular use-retouch due to cutting and/or scraping hard material, such as wood or bone/antlers. The dimensions are $90.7 \times 33.7 \times 11.5 \mathrm{~mm}$.

In Fig. 5,1, there is a slightly offset chunky blade with asymmetrical a sub-trapezoid cross-section and a somewhat twisted side-profile. On the proximal end left lateral edge, near the base, there is an unretouched indentation with use-wear traces. The distal part of the edge is partly retouched, partly shows use-retouch/cryoturbation retouch and several splinterings. The proximal end of the slightly curved right edge is inversely retouched in a length of about $49.3 \mathrm{~mm}$; and continuously, the distal end is directly retouched in a length of $53.0 \mathrm{~mm}$. Along this edge, there are only moderate use-wear traces. The dimensions are $109.6 \times 44.1 \times 20.3 \mathrm{~mm}$.

10 WeChler 1993, 60-61, cited in CzIEsla 2008, 431.

11 VERMEERSCH 1980.

12 WENZEL 2012, 635-636. 


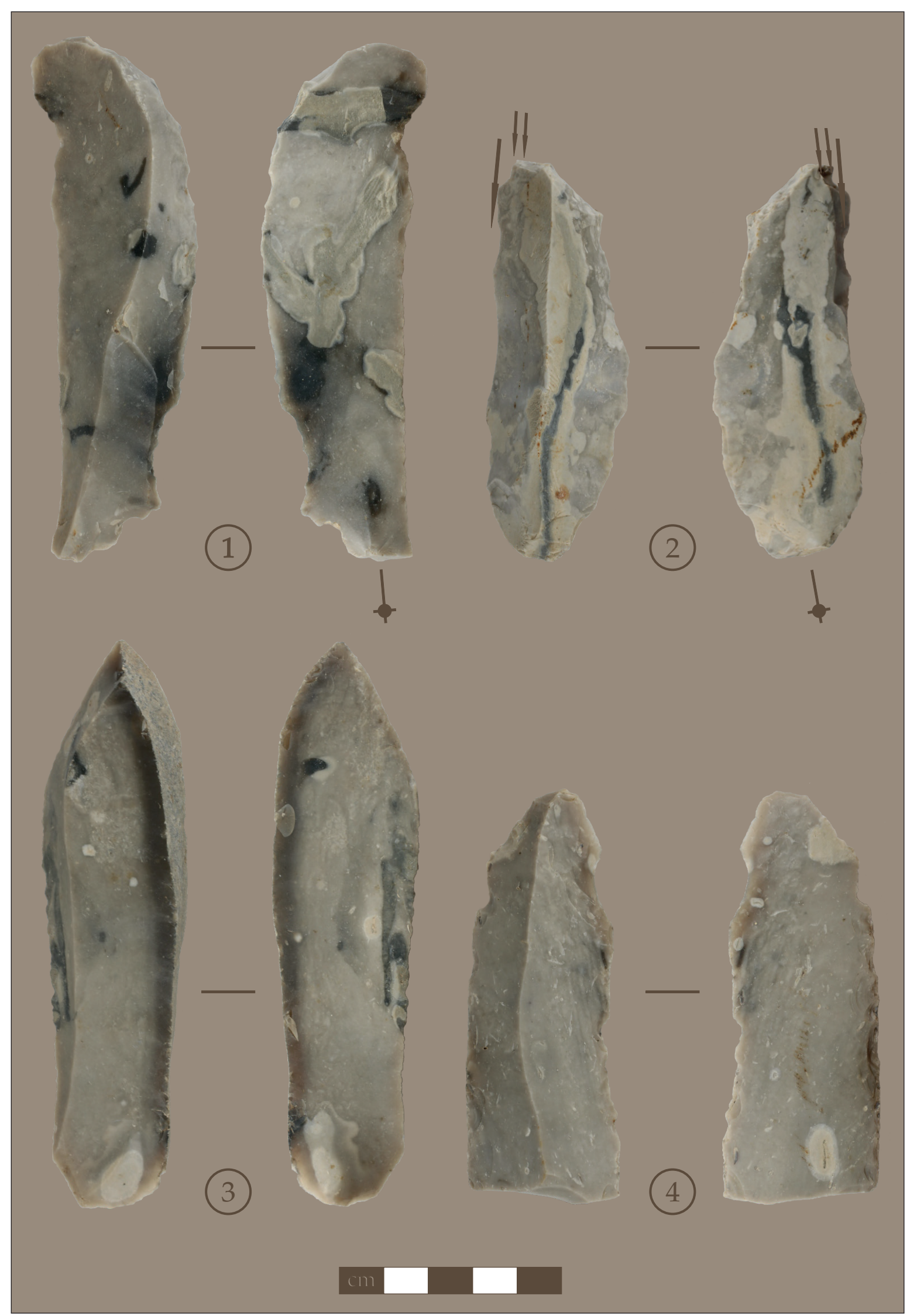

Fig. 4. Selected artefacts. 1 - retouched blade, 2 - combination tool (retouched blade and burin), 3 - unretouched blade, 4 - blade with "use-retouche". 


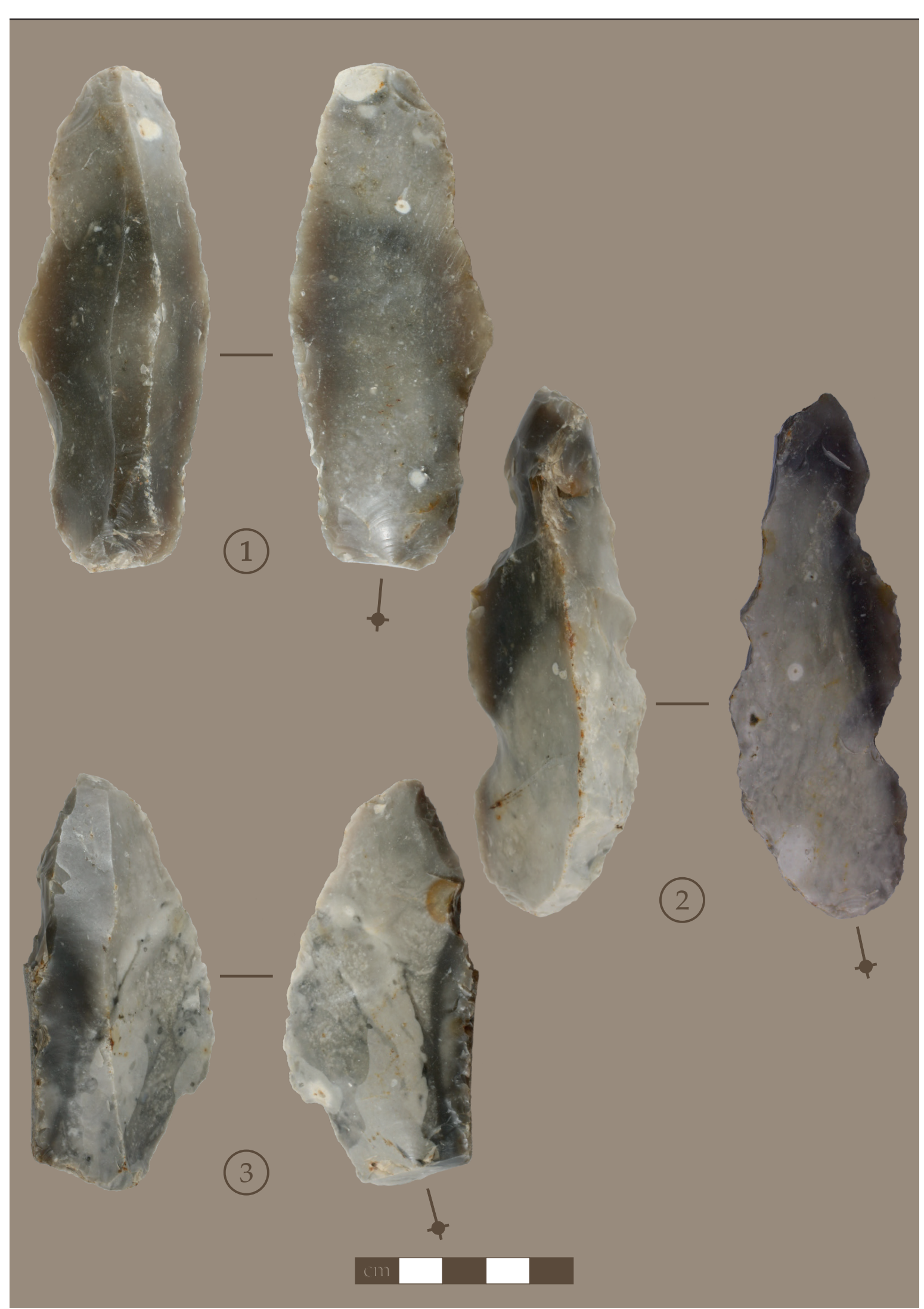

Fig. 5. Selected artefacts. 1 - partially retouched blade, 2 - retouched and notched blade with a borer-like distal end, 3 - typical expedient tool. 
A combination tool was made on a curved chunky blade with an asymmetric cross-section and curved twisted profile (Fig. 5,2). The distal end is pointed, the intensive use-wear traces and the several renewals suggest that this part might have been used as a "borer" for hard material, such as wood. Along the left lateral edge, there are two notches; the lower notch is unretouched but has partially use-retouch. The upper notch is roughly retouched, and also shows traces of intensive scraping activity of hard material. The thick and very steep right edge is roughly denticulated. Through the inverse retouching of the proximal end beneath the lower notch, and the curved-lined retouching of the right edge, the butt and the bulb of the blade are not visible. The dimensions are $111.2 \times 35.8 \times 20.5 \mathrm{~mm}$.

There is a typical expedient tool in Fig. 5,3. It was made on a large-sized offset blade (elongated flake) with an asymmetrical sub-trapezoid cross-section and straight side-profile. The left lateral edge is almost perpendicular to the lower face; it is covered with the natural surface of the flint nodule. The distal end is somewhat pointed; on the right side of the "tip", there is a short oblique section bearing use-retouch. On the left side of the "tip", on the lower face, there are some irregular removals resembling burin blows. In conclusion, the distal end might have been used as a "pick". The lateral edges are not retouched but show sporadic use-wear traces. The dimensions are $92.6 \times 44.9 \times 19.9 \mathrm{~mm}$.

In Fig. 6,1, there is an unretouched blade with an asymmetrical sub-triangular cross-section and a straight side-profile. Both edges have use-retouch and/or cryoturbation retouch. The dimensions are $83.0 \times 34.9 \times 12.2 \mathrm{~mm}$. The right edge of the relatively short flake in Fig. 6,2 shows the signs of working hard material. The dimensions are $55.9 \times 40.7 \times 16.5 \mathrm{~mm}$. The curved distal end of a short and broad flake in Fig. 6,3 was retouched and may have been used as an "end-scraper". The dimensions are $63.9 \times 53.5 \times 11.3 \mathrm{~mm}$. The flake in Fig. 6,4 shows no traces of further elaboration. Both edges show moderate cryoturbation retouch. The dimensions are $67.7 \times 38.2 \times 15.4 \mathrm{~mm}$. There is a somewhat atypical combination tool (Fig. 6,5). The blank for the tool manufacturing was a semi-cortical flake with a sub-triangular cross-section and a somewhat wavy side-profile. The straight distal is half-steeply retouched and was probably used as an end-scraper. The working edge shows no traces of renewals. In the mid-part of the left lateral edge, there is a small-sized retouched notch. The dimensions are $63.6 \times 33.0 \times 16.6 \mathrm{~mm}$.

\section{Discussion and conclusion}

Concerning the raw material used, the flint varieties with the banded structure are rather unusual in Schleswig-Holstein. They are much more likely to originate from Lower Saxony or perhaps Mecklenburg-Western Pomerania or areas adjacent to the south. For decades, many researchers have studied the possible physio-chemical factors of flint patination. ${ }^{13}$ Here only a brief explanation will be given of this complex geochemical process. The surface of some siliceous stone artefacts, especially the different kinds of flints, are subject, over some time and under certain environmental conditions, to various kinds of chemically induced surface alteration, called patination. The rate of patination is influenced by a combination of several factors, such as the predominant mechanism by which water and other patination agents penetrate stone artefacts, the nature of impurities, the permeability, texture, and microstructure of the stone, and environmental factors, such as temperature and soil chemistry. Impurities are of particular importance since artefacts containing chem- 
ically unstable impurities (carbonates, clay minerals, iron sulfide, iron, and manganese oxides) are susceptible to patination. According to Glauberman and Thorson, the patination is more related to the depositional context than sub-aerial surface exposure. ${ }^{14}$

As regards the technological characteristics, the application of the "direct percussion with a hard hammer" technique and the presence of the thick artefacts contradict the Palaeolithic or Mesolithic origin of the assemblage. Only in the case of the flint axe is a possible Mesolithic association conceivable. The applied flaking technique is very rare in Schleswig-Holstein, and if it is present then it is in the Neolithic or Copper/Bronze Age. As we mentioned before, similar artefacts are also frequent in Trichterbecher assemblages, so it is possible, that all pieces came from the very same site. According to the available information, laterally retouched, large blades, end-scrapers and pieces with surface retouch are common in early Trichterbecher assemblages in Northern Germany ${ }^{15}$ It cannot be excluded that the flake axe, together with the rest of the assemblage, might have come from southern Sweden or Sealand in Denmark.

Alternatively, if the edges of the artefacts are not worn out or rolled, then along the edges of all artefacts, traces of some kind of damage can be observed. It is worth noting that the edge damage has a "cryoturbation retouch" impression. Various periglacial soil movements, such as cryoturbation and gelifluction, which are limited in time to glacial periods, can give rise to a "cryoturbation retouch" that can strongly resemble an artificial retouch. Dick Stapert lists several distinctive characteristics: 'in the case of natural 'retouch' small 'teeth' often develop along the 'retouched' sides. Alternating retouch is also often present" ${ }^{16}$ Mechanical or physical weathering involves the breakdown of a part or parts of the lithic artefact through direct contact with atmospheric conditions, such as heat, water, ice, and pressure.

Since no information on the archaeological site or sites is available, this partly taphonomic effect cannot be interpreted. In general, it is assumed that the transition to the sedentary lifestyle and the increase in social complexity are correlated with a change in emphasis on lithic technologies, which went from being formal technologies to being more expeditious technologies. In contrast to "curation", 17 "expediency" has been defined as "minimized technological effort under conditions where time and place of use are highly predictable". ${ }^{18}$

The local raw material is brought to the site with no prior modification; the cores have no standardized shapes (generalized, amorphous cores). ${ }^{19}$ Taking into account ethnographic descriptions, the following aspects are considered as distinctive features of expeditious core technology.

- the flaking techniques do not control the form (shape) of the resulting flakes;

- there is no explicit distinction between "tools" and "waste"; every debitage product is considered as a potential tool;

- the tools are rarely modified.

If a piece has an unsuitable shape, or its edge is dulled from use, it is usually discarded.$^{20}$ According to numerous scholars, expedient technology has other fairly essential characteristics. For example,

Glauberman - Thorson 2012, 22.

Kieselbach 2012, 901-993; Midgley 1992, 253-254.

STAPERT 1976, 29.

BINFORD 1977; BINFORD 1979.

NELSON 1991, 64.

JoHNSON 1986.

PARRY - Kelly 1987, 286. 


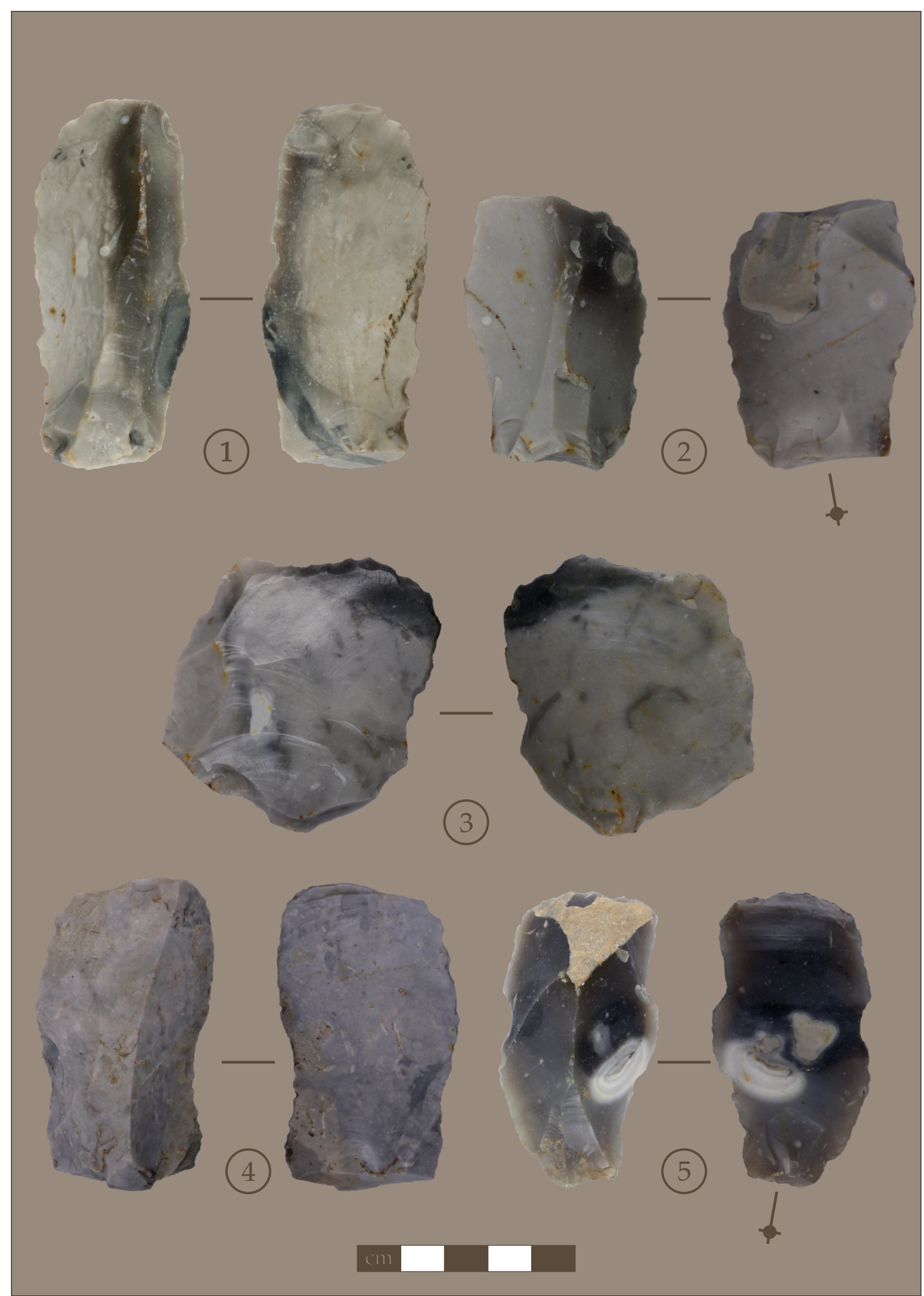

Fig. 6. Selected artefacts. 1, 3 - unretouched blades with use traces, 4 - unretouched blade, 5 - atypical combination tool (end-scraper and notches). 
Brad Koldehoff ${ }^{21}$ suggests that the discarded flakes, used with little modification, are the best examples of expeditious tools. In general, a high frequency of cortical flakes is expected in a lithic assemblage with expedient technology. ${ }^{22}$ Jay K. Johnson ${ }^{23}$ states that among others, the near absence of evidence for the rejuvenation of worn edges suggests that flakes may have been the object rather than the by-product of the core industry. William Andrefsky Jr. has suggested that the availability of raw materials must be considered before lithic production technologies can be linked to prehistoric settlement patterns. Non-formal expeditious tools tend to be made from low-quality raw materials, depending on whether they are readily available or not; instead, formal tools tend to be made from high-quality raw materials, especially when they are not readily available. ${ }^{24}$

Generally, but not necessarily, the use of expeditious technologies has been associated with a decrease in the general mobility of populations, that is with the change to sedentarism, which produced a decrease in the need to produce portable formal tools. Expedient technology can be employed also by highly mobile hunter-gatherers when raw material is abundant or locally available. ${ }^{25}$ Although "expeditious" and "formal" technologies have generally been seen as dichotomous categories, the two have generally been shown to occur simultaneously in a given population. ${ }^{26}$ And finally, to enlighten the complexity of this topic, Robert J. Jeske should be cited. ${ }^{27}$ According to him, the reduction of energy investment in lithic technology (resulting in expeditious technologies instead of the more formal ones) could also have been a response to the population's need to increase energy in other social activities not related to production, such as political alliances and warfare.

Overall, the lithic assemblage is very instructive; all the large-sized non-formal tools suggest the intensive use of the tools on hard materials, such as wood or bone/antlers. These activities are also more readily assigned to a sedentary lifestyle and seem to prove the rather younger prehistoric origin of the assemblage, possibly having a close connection with the Trichterbercher culture and the earliest farmers of Northern Germany.

\section{Acknowledgment}

We would like to express our gratitude to András Marton for donating selected finds from his collection to the ELTE University and for making this paper possible. We would like to thank Gábor Ilon for providing the information about the existence of this assemblage.

\section{References}

ANDREFSKy, W. Jr. 1994: Raw-Material Availability and the Organization of Technology. American Antiquity 59:1, 21-34. DOI: 10.2307/3085499

Binford, L. R. 1977: Forty-Seven Trips. In: Wright, R . V. S. (ed.): Stone Tools as Cultural Markers. Canberra, 24-36.

Binford, L. R. 1979: Organization and Formation Processes: Looking at Curated Technologies. fournal of Anthropological Research 35, 255-273. DoI: 10.1086/jar.35.3.3629902 
Совв, C. R. -Webв, P. A. 1994: A Source Area Perspective on Expedient and Formal Core Technologies, North American Archaeologist 15:3, 197-219.

CzIesla, E. 2008: Bandkeramik zwischen Elbe und Oder. Germania 86:2, 405-464.

Fiedler, L. - Hubbert, J. 2017: Beile, Spitzhauen und Keulen der Mittelsteinzeit zwischen Rhein- und Werra - Gewissheit und Erwägungen. Arbeitsgemeinschaft Altsteinzeit und Mittelsteinzeit Hessen. http://altsteinzeit-hessen.de/wp-content/uploads/2017/10/Fiedler-Beile-2.pdf

Glauberman, Ph. J. - Thorson, R. M. 2012: Flint Patina as an Aspect of "Flaked Stone Taphonomy": A Case Study from the Loess Terrain of the Netherlands and Belgium. Fournal of Taphonomy 10:1, 21-43.

HoneA, K. H. 1964: The Patination of Stone Artifacts. Plains Anthropologist 9, 14-17. Dor: 10.1080/2052546. 1964.11908372

Hurst, V. J. - Kelly, A. R. 1961: Patination of Cultural Flints. Science 134, 251-256. DoI: 10.1126/science. 134.3474 .251

Inizan, M.-L. - Reduron-BAllinger, M. - Roche, H. - Tixier, J. 1999: Technology and Terminology of Knapped Stone. Préhistoire de la Pierre Taillée 5. Meudon.

Jeske, R. J. 1992: Energetic Efficiency and Lithic Technology: An Upper Mississippian Example. American Antiquity 57:3, 467-481. DOI: 10.2307/280935

Johnson, J. K. 1986: Amorphous Core Technologies in the Midsouth. Midcontinental fournal of Archaeology 2, 135-151.

Juel Jensen, H. - Brinch Petersen, E. 1985: A Functional Study of Lithics from Vaenget Nord. A Mesolithic Site from Vedbaek, N. E. Sjaelland. Journal of Danish Archaeology 4, 40-51. DOI: 10.1080/0108464X.1985.10589934

Kieselbach, P. 2012: Gerätebestand des Jung- bis Endneolithikums. In: Floss, H. (ed.): Steinartefakte vom Altpaläolithikum bis in die Neuzeit. Tübingen Publications in Prehistory. Tübingen, 901-922.

Koldehoff, B. 1987: The Cahokia Flake Tool Industry: Socioeconomic Implications for Late Prehistory in the Central Mississippi Valley. In: Johnson, J. K. - Morrow, C. A. (eds): The Organization of Core Technology. Boulder, 151-185.

Madsen, B. 1984: Flint Axe Manufacture in the Neolithic: Experiments with Grinding and Polishing of Thin-Butted Flint Axes, fournal of Danish Archaeology 3:1, 47-62. DOI: 10.1080/0108464X.1984.10589911

Midgley, M. S. 1992: TRB culture: The first farmers in the north European plain. Edinburgh.

Nelson, M. C. 1991: The Study of Technological Organization. In: Schiffer, M. B. (ed.): Archaeological Method and Theory 3, 57-100.

Parry, W. - Kelly, R. L. 1987: Expedient Core Technology and Sedentism. In: Johnson, J. K. - Morrow, C. A. (eds): The Organization of Core Technology. Boulder, 285-304.

Pratsch, S. 2011: Mesolithic antler artefacts in the North European Plain. In: Baron, J. - Kufel-Diakowska, B. (eds): Written in Bones. Studies on Technological and Social Contexts of Past Faunal Skeletal remains. Wrocław, 79-92.

Solneim, S. - Fossum, G. - Knutsson, H. 2018: Use-wear analysis of early Mesolithic flake axes from South-eastern Norway. Journal of Archaeological Science: Reports 17, 560-570. DOI: 10.1016/j.jasrep.2017.12.017

StApert, D. 1976: Some natural surface modifications on flint in the Netherlands. Palaeohistoria 18, 18-41.

Thacker, P. T. 1996: Hunter-Gatherer Lithic Economy and Settlement Systems: understanding Regional Assemblage Variability in the Upper Paleolithic of Portuguese Estremadura. In: Odell, G. H. (ed.): Stone Tools: Theoretical Insights into Human Prehistory. New York, 101-124. DOI: 10.1007/978-1-4899-0173-6_5 
Vermeersch, P. M. 1980: Quelques idées sur l'origine de la hache polie en silex en europe occidentale. Helinium 20, 260-268.

WechleR, K.-P. 1993: Mesolithikum - Bandkeramik - Trichterbecherkultur. Zur Neolithisierung Mittel- und Ostdeutschlands aufgrund vergleichender Untersuchungen zum Silexinventar. Beiträge zur Ur- und Frühgeschichte Mecklenburg-Vorpommerns 27. Lübsdorf.

Wenzel, S. 2012: Kern- und Scheibenbeile. In: Floss, H. (ed.): Steinartefakte vom Altpaläolithikum bis in die Neuzeit. Tübingen Publications in Prehistory. Tübingen, 631-638. 